\title{
Different expression levels of glycans on leukemic cells-a novel screening method with molecularly imprinted polymers (MIP) targeting sialic acid
}

\author{
Zahra El-Schich $^{1}$ - Mohammad Abdullah ${ }^{1} \cdot$ Sudhirkumar Shinde $^{1} \cdot$ Nishtman Dizeyi $^{2}$. \\ Anders Rosén $^{3}$ • Börje Sellergren ${ }^{1}$ - Anette Gjörloff Wingren ${ }^{1}$ (D)
}

Received: 4 April 2016 / Accepted: 15 July 2016 /Published online: 31 July 2016

(C) The Author(s) 2016. This article is published with open access at Springerlink.com

\begin{abstract}
Sialic acid (SA) is normally expressed on the cell membranes and is located at the terminal position of the sugar chains. SA plays an important role for regulation of the innate immunity, function as markers of the cells and can be recognized by a variety of receptors. Interestingly, the level of SA expression is increased on metastatic cancer cells. The availability of specific antibodies against SA is limited and, therefore, biomarker tools for detection of SA are lacking. We have recently presented a novel method for specific fluorescence labeling of SA molecular imprinted polymers (MIP). Here, we have performed an extended screening of SA expression by
\end{abstract}

Zahra El-Schich

Zahra.el-schich@mah.se

Mohammad Abdullah

emdotey@hotmail.com

Sudhirkumar Shinde

Sudhirkumar.shinde@mah.se

Nishtman Dizeyi

nishtman.dizeyi@med.lu.se

Anders Rosén

anders.rosen@liu.se

Börje Sellergren

borje.sellergren@mah.se

Anette Gjörloff Wingren

anette.gjorloff-wingren@mah.se

1 Department of Biomedical Sciences, Faculty of Health and Society, Malmö University, Malmö, Sweden

2 Department of Translational Medicine, Lund University, Malmö, Sweden

3 Department of Clinical and Experimental Medicine, Division of Cell Biology, Linköping University, Linköping, Sweden using SA-MIP and included four different chronic lymphocytic leukemia (CLL) cell lines, conveniently analyzed by flow cytometry and fluorescence microscopy. SA expression was detected in four cell lines at different levels, and the SA expression were verified with lectin-FITC. These results show that SA-MIP can be used as a plastic antibody for detection of SA using both flow cytometry and fluorescence microscopy. We suggest that SA-MIP can be used for screening of different tumor cells of various stages, including CLL cells.

Keywords Chronic lymphocytic leukemia · Lectin · Molecular imprinting polymers $\cdot$ Sialic acid

\section{Introduction}

Glycans, or polysaccharides, are present on the outer surface of most eukaryotic cells and are involved in various cell processes, including protecting the cells from intruders and in cellular connection. Attachment of $O$ - and $N$-linked glycans to proteins for the generation of glycoproteins is very common structural motifs [1]. Sialic acid (SA) plays an important role for regulation of the innate immunity and may have an inhibitory effect on complement activation [2]. SA's attached at the end of glycan chains provides a negative charge on the cell surface, which is required for trafficking of cells. SA functions as a cellular marker and can be recognized by a variety of receptors [3]. In the late $80 \mathrm{~s}$, an association between SA and cancer was discovered, especially on metastatic cancer $[4,5]$. Fuster reported that overexpression of SA in metastatic cancer controls tumor cell growth and differentiation by interfering with neural cell adhesion molecule signaling at cell-cell contacts $[1,6]$. Overexpression of tumor-associated SA in metastatic bladder tumors has been shown, and it was speculated 
whether there is a benefit of the combination of anti-SA immunotherapy and anti-proliferative drugs [7].

Analyzing and determining these glycosylation motifs is therefore an important diagnostic goal but the task is a challenge due to the limited availability of appropriate lectins and glycan-specific antibodies $[8,9]$. This calls for the development of alternative glycan-specific probes and cell imaging technologies. Recent reports have shown that synthetic probes based on host guest chemistry [10] or molecular imprinting technology [11] can be used for glycan selective staining of cells and tissues. Using the former approach, $\mathrm{Xu}$ and colleagues developed fluorescent sensors based on two boronic acids linked to a functionalized peptide for detection of cellsurface cancer-associated glycans [10]. On the other hand, imaging probes based on phenylboronic acid-modified quantum dots have also been used, allowing specific labeling of SA on living cells [12]. However, this approach has the weakness of targeting diols in a non-specific manner.

Molecular imprinting, as a design concept, is in this context more attractive. Artificial receptors are produced by allowing a network polymer to assemble in the presence of a template. After removing the template, the resulting molecularly imprinted polymer (MIP) can be used as an artificial antibody [13]. A key advantage of this technique is that it can be used for recognizing less immunogenic targets such as glycans [14]. Moreover, compared with antibodies, MIPs can be produced at low cost and feature superior robustness and long-term stability [15].

Recently, different monosaccharide imprinting procedures were used to produce fluorescently labeled nanoparticle probes displaying an unprecedented affinity for the targeted terminal monosaccharides in cell staining experiments [16]. Based on a ternary complex imprinting approach, we developed imprinted core-shell nanoparticles showing an exceptional affinity for cell surface SA-glycans. The probe comprised a nitrobenzoxadiazole (NBD) fluorescent reporter group showing enhanced emission intensity in presence of the SA-guest. In flow cytometry and fluorescence microscopy investigations, the SA-MIP selectively targeted two different prostate cancer cell lines DU145 and PC3, as well as the T leukemia cell line Jurkat. The SA expression was verified with lectin-FITC [11].

In this study, we have performed an extended screening of SA expression by using SA-MIP using four different chronic lymphocytic leukemia (CLL) cell lines, conveniently analyzed by flow cytometry and fluorescence microscopy. Indeed, SA expression was detected in all four cell lines and at different levels.

\section{Material and methods}

\section{Cell culture}

Four CLL cell lines were used, HG3, CI, Wa-osel, and AIII [17]. The cell lines were cultured in RPMI-1640 medium
(Invitrogen, San Diego, CA, USA) supplemented with $10 \%$ fetal bovine serum (FBS, Invitrogen) and $50 \mu \mathrm{g} / \mathrm{mL}$ gentamycin (Invitrogen) and incubated in $37{ }^{\circ} \mathrm{C}$ with $5 \%$ $\mathrm{CO}_{2}$ in $100 \%$ humidity.

\section{Preparation of polymers}

The polymers (SA-MIP) were prepared as described previously [11]. In brief, the dried SA-MIP were resuspended in water/ water and analyzed using (3\% methanol, Sigma-Aldrich Co., St. Louis, MI) and sonicated for 8 min with a VWR sonicator. The stock solution of $0.8 \mathrm{mg} / \mathrm{ml}$ was further sonicated and diluted prior to use.

\section{Flow cytometry analysis of SA-MIP and lectin-FITC}

$1 \times 10^{6}$ cells/sample were stained with either SA-MIP, lectinFITC (Sigma-Aldrich) or left unstained as a control. The cells of each CLL cell line were washed twice with $2 \mathrm{ml}$ phosphatebuffered saline (PBS, Invitrogen), and fixed with $1 \mathrm{ml}$ of $4 \%$ formaldehyde (Sigma-Aldrich) and incubated for $20 \mathrm{~min}$ at room temperature (RT). After fixation, the cells were washed three times with $2 \mathrm{ml}$ PBS and, thereafter, two times with $2 \mathrm{ml}$ $3 \%$ methanol. Five hundred microliters of a sonicated polymer suspension of concentrations of 400, 200, 80, and $40 \mu \mathrm{g} / \mathrm{ml}$, respectively, was added to the cells, and $500 \mu \mathrm{L}$ of $3 \%$ methanol was used as a negative control. The cells were incubated with SA-MIP for $90 \mathrm{~min}$ in $37^{\circ} \mathrm{C}$ and were thereafter washed three times with $2 \mathrm{ml} 3 \%$ methanol/water and analyzed using flow cytometry (BD Biosciences, Accuri C6 Flow Cytometry, NJ).

For lectin staining, cells were incubated with $500 \mu \mathrm{l}$ of lectin-FITC of concentrations $100,50,25$, and $10 \mathrm{ng} / \mathrm{ml}$ or left unstained as a negative control with $500 \mu \mathrm{l}$ PBS. The cells were incubated in the dark for $20 \mathrm{~min}$, on ice, and were thereafter washed three times with $2 \mathrm{ml}$ PBS and analyzed by flow cytometry.

\section{Ligand binding assay of SA based on flow cytometry}

A ligand binding assay based on the flow cytometry analysis, i.e., quantification of cellular fluorescence of the CLL cell lines was performed. The saturation capacity of the binding sites in the SA-MIP was $10 \mu \mathrm{mol} \mathrm{g} \mathrm{g}^{-1}$ [11]. The binding curve was fitted by non-linear regression to a Langmuir mono-site model using the Prism 6 curve fitting software (Graph pad Inc.).

\section{Fluorescence microscopy of SA-MIP and lectin-FITC}

Fifty thousand cells/sample of HG3 cells were adhered to poly-lysine treated slides (Thermo Scientific, MA) for $2 \mathrm{~h}$, at $37^{\circ} \mathrm{C}$ with $5 \% \mathrm{CO}_{2}$ in $100 \%$ humidity. After the incubation, 
$\mathbf{A}_{120}$

—40 ロ $80 \quad \square 200 \quad \square 400$

$$
100
$$

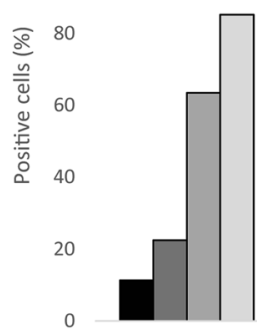

HG3

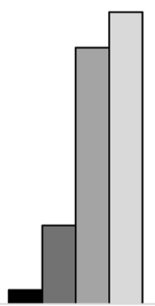

$\mathrm{Cl}$

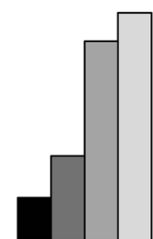

Wa-osel

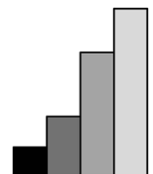

Alll
$\mathbf{B}_{200000}$

— $40 \quad \square 80 \quad \square 200 \quad \square 400$

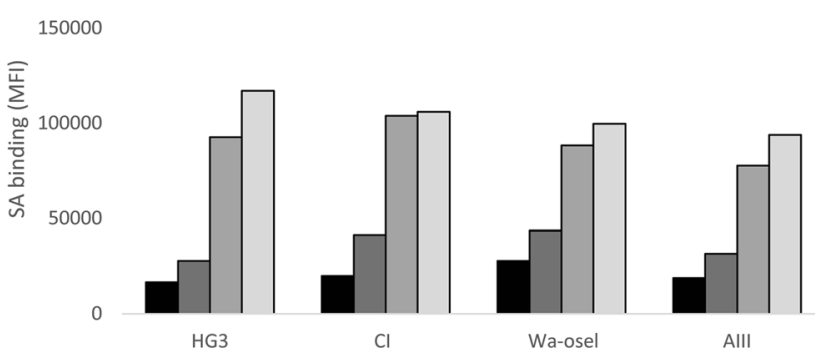

Fig. 1 SA expression on the four CLL cell lines. Results of HG3, CI, Waosel, and AIII cells stained with different concentrations of SA-MIP. Flow cytometry results present $\mathbf{a}$ the positive cells for SA and $\mathbf{b}$ the MFI of the SA binding. One representative experiment out of two performed is shown the cells were washed three times with PBS and fixed with $100 \mu 14 \%$ formaldehyde for $10 \mathrm{~min}$. Thereafter, the cells were washed three times with PBS and two times with $3 \%$ methanol, and the cells were incubated with $100 \mu \mathrm{l}$ sonicated SA-MIP at concentration of $100 \mu \mathrm{g} / \mathrm{ml}$ or left unstained with $100 \mu 13 \%$ methanol at $37^{\circ} \mathrm{C}$ for $60 \mathrm{~min}$. After the incubation, the cells were washed four times with $3 \%$ methanol and, thereafter, twice with PBS, incubated with 300 nM DAPI in PBS (Thermo Fisher Scientific, Carlsbad, CA), and incubated for 4 min at RT. After three more washes with PBS, the cells were mounted with one drop of mounting medium Prolong ${ }^{\circledR}$ Gold antifade reagent (Molecular probes).

For lectin staining, HG3 cells were adhered to polylysine-treated slides and, thereafter, fixed with $1 \mathrm{ml} 4 \%$ formaldehyde, for $10 \mathrm{~min}$ at RT and, thereafter, washed three times with PBS. The cells were incubated with $100 \mu \mathrm{l}$ of lectin-FITC of concentration $100 \mathrm{ng} / \mathrm{ml}$ or left unstained as a negative control with $100 \mu \mathrm{l}$ PBS. The cells were incubated with lectin-FITC at RT for $60 \mathrm{~min}$. Next, the cells were washed three times with PBS and then incubated with $300 \mathrm{nM}$ DAPI in PBS and incubated for $4 \mathrm{~min}$ at RT. After three washes with PBS, the cells were mounted with one drop of mounting medium Prolong® Gold antifade reagent. The stained cells were then analyzed using fluorescence microscopy (EVO® LS 10, Carl Zeiss, Jena, Germany).
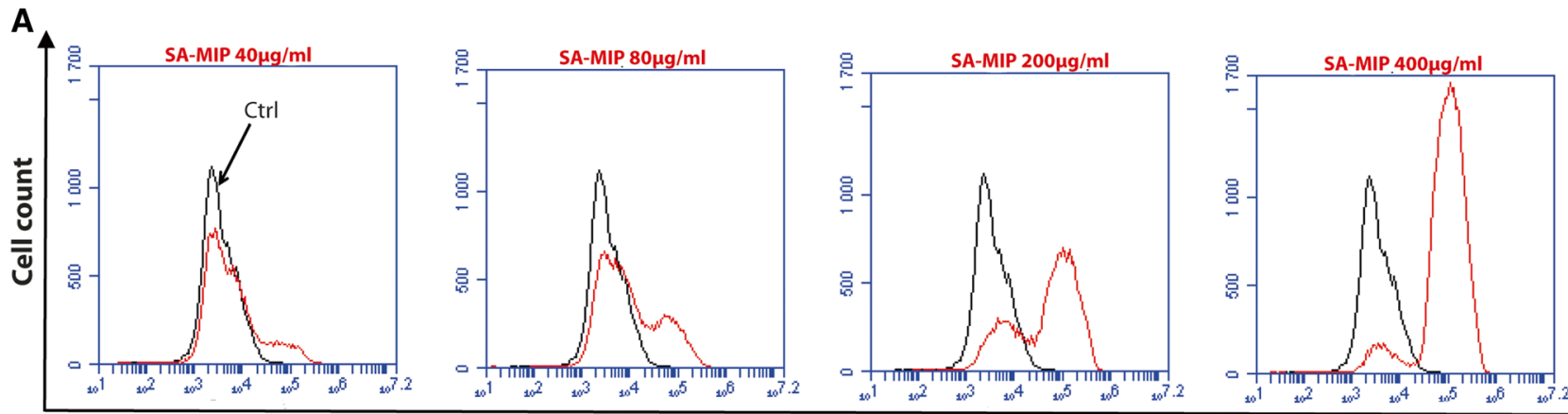

SA-MIP bindning (MFI)

B
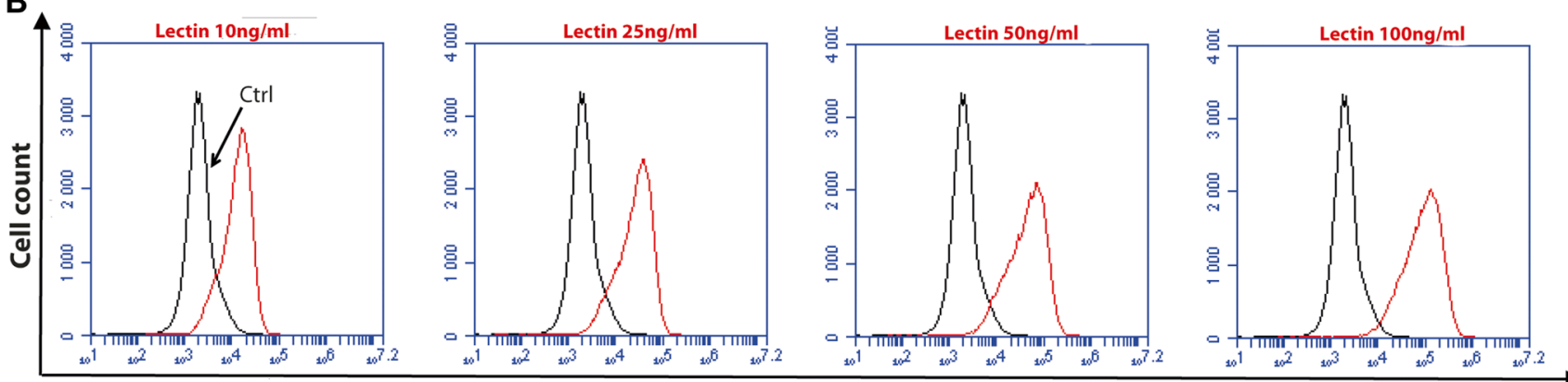

\section{Lectin binding (MFI)}

Fig. 2 SA and lectin binding on HG3 cells. Flow cytometry analysis of HG3 cells with different concentrations of SA-MIP (a) and lectin-FITC (b). Black traces show the unstained samples, while the red traces show
SA-MIP (a) and lectin-FITC (B). The results are presented as MFI. One representative experiment out of two performed is shown 


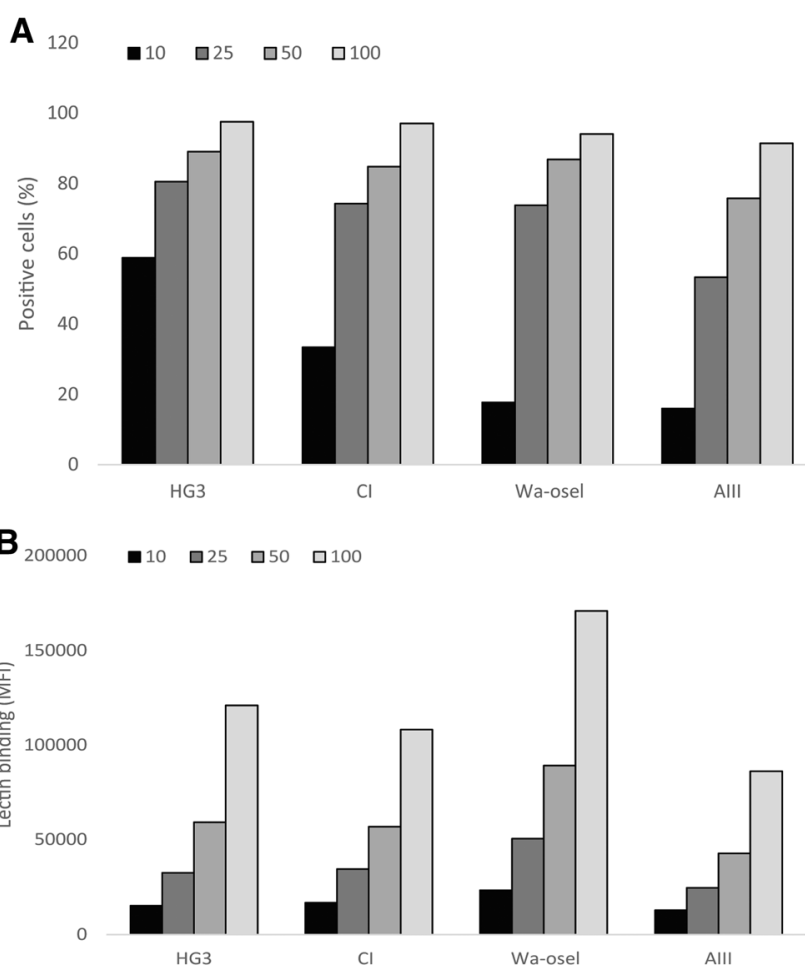

Fig. 3 Lectin binding on the four CLL cell lines. Results of HG3, CI, Wa-osel, and AIII cells stained with different concentrations of lectinFITC. Flow cytometry results present a the positive cells for lectin binding and $\mathbf{b}$ the MFI of the lectin binding. One representative experiment out of two performed is shown

\section{Results}

\section{Expression of SA in the four CLL cell lines HG3, CI, Wa-osel, and AIII as detected by flow cytometry}

The surface expression of SA in the four CLL cell lines was investigated by flow cytometry. The fluorescence intensity of the cell lines was different after staining with SA-MIP (200 and $400 \mu \mathrm{g} / \mathrm{ml}$ ) (Fig. 1a). HG3 and CI showed a slightly higher percentage of positive cells compared to the cell lines Wa-osel and AIII. When comparing the mean fluorescence intensity (MFI) among the four CLL cell lines, there were however no major differences (Fig. 1b). Figure 2 displays the histogram for the HG3 cell line with different concentrations of SA-MIP (Fig. 2a) and lectin-FITC (Fig. 2b). An increase in binding for SA-MIP to HG3 could be seen, but the lectin-FITC binding was high even at lower concentrations of the lectin. However, the lectin binding with the $10 \mathrm{ng} / \mathrm{ml}$ concentration varied between the CLL cell lines (Fig. 3), being higher for HG3 and CI compared to the cell lines Wa-osel and AIII (Fig. 3a).

\section{HG3 and CI showed highest specific binding in a ligand binding assay}

In a saturation ligand binding assay based on the flow cytometry analysis, quantification of cellular fluorescence of the CLL cell lines was possible by using one site specific binding with Hill slope. The specific binding of SA was higher on HG3 and CI compared to Wa-osel and AIII, (Fig. 4).

\section{SA expression in the HG3 cell line as detected by fluorescence microscopy}

In order to visualize the glycans on the surface of the CLL cell line HG3, the cells were stained with either SA-MIP (Fig. 5a), lectin-FITC (Fig. 5b) or left unstained. All samples were stained with DAPI for nuclear visualization and analyzed with fluorescence microscopy. Overall, the SA-MIP led to a membrane staining of the cells in a qualitatively similar way as lectin-FITC. Staining with lectin-FITC led to a ring-shaped fluorescence pattern all over the cell membrane.

\section{Discussion}

We have previously reported successful cell imaging experiments, where SA-MIP particles selectively stained different cell lines in correlation with the SA expression levels [11]. This was further verified by enzymatic cleavage of SA and by staining using a FITC-labeled lectin. SA plays an important role in a variety of biological processes in cells. In this study, we were primarily interested to verify any correlations with the aggressiveness of the CLL cell lines and SA expression levels [17].
Fig. 4 Quantification of cellular fluorescence of the four CLL cell lines. Specific ligand binding assay based on flow cytometry for the four CLL cell lines stained with different concentrations of SA-MIP. For each cell line, the $\mathrm{Kd}(\mu \mathrm{M})$ and $\mathrm{B}_{\max }(\%$ positive cells) are shown

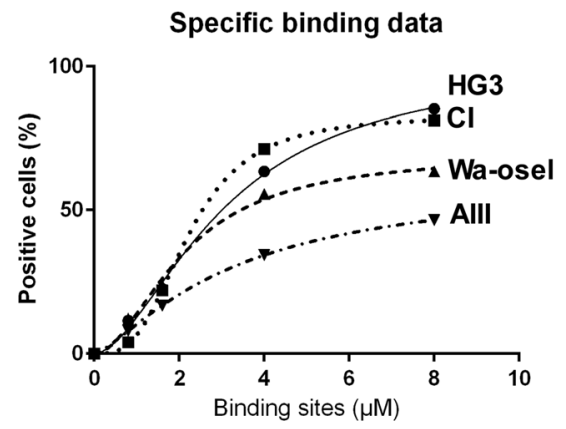

\begin{tabular}{|c|c|c|}
\hline & $\mathrm{Kd}(\mu \mathrm{M})$ & $\mathrm{Bmax}(\%$ positive cells) \\
\hline $\mathrm{HG} 3$ & $3,1 \pm 0,4$ & $102 \pm 8,8$ \\
\hline $\mathrm{Cl}$ & $2,2 \pm 0,02$ & $83 \pm 0,5$ \\
\hline Wa-osel & $2,1 \pm 0,3$ & $70 \pm 6$ \\
\hline AlII & $3,3 \pm 0,06$ & $61 \pm 0,6$ \\
\hline
\end{tabular}


Fig. 5 Fluorescence microscopy images of HG3 cells stained with either SA-MIP or lectin-FITC. HG3 cells were stained with either SA-MIP $(100 \mu \mathrm{g} / \mathrm{ml}$, left image) or lectin-FITC (100 ng/ml, right image). For nuclear visualization, all samples were stained with DAPI. Scale bar $=10 \mu \mathrm{m}$
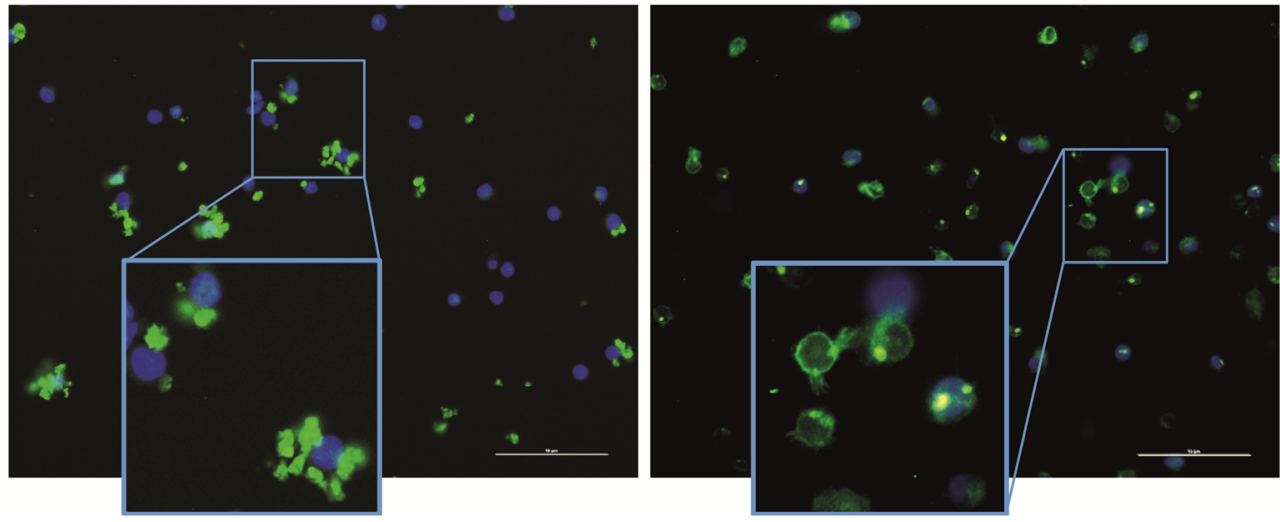

SA expression is enhanced in metastatic cancer cells [18, 19]. CLL cells are CD5+/CD19+ B cells originating from antigen-experienced B1-like B-cells [20, 21]. Indeed, both normal and malignant leukocytes utilize adhesive interactions to migrate throughout the body [22]. Selectins and the sialic-acidbinding immunoglobulin-like lectins (Siglecs) are the intrinsic receptors within vertebrate cells that recognize the SA. Selectins have an important role in the spread of epithelial cancers through the bloodstream. Studies in selectin-deficient mice further confirmed a pivotal role of these glycan-binding proteins in various models of cancer metastasis [23-25]. Siglec-2 (also known as CD22) is a member of the Siglec family, expressed mostly on B cells, recognizes SA as a ligand [26]. The four CLL cell lines used in this study, HG3, CI, Waosel, and AIII, all expressed SA at different levels. For each cell line, we show a dose-dependent increase in the number of SA-positive cells as analyzed by flow cytometry. Interestingly, two of the CLL cell lines, HG3 and CI, expressed higher levels of SA compared to the other CLL cell lines, Wa-osel and AIII. This is in line with the fact that the aggressiveness of the cancer cells correlates with increasing SA levels [18, 19]. HG3 and CI have an unmutated immunoglobulin heavy chain variable $(I G H V)$ gene, which is associated with high cell proliferation and a more aggressive form of CLL compared with Wa-osel and AIII cells, which have a mutated $I G H V$ gene, a signature of less aggressive indolent CLL cells [17].

Analyzing SA on leukocytes can be technically complex, since SA has been shown to be masked by endogenous sialylated ligands [27]. Sialidase treatment or cellular activation is necessary to unmask these sites, possibly by endogenous sialidase efficiency. However, in this study, we could not detect any differences in SA expression after anti-IgM ligation for up to $72 \mathrm{~h}$ of the CLL cell lines (data not shown).

Many studies describe changes in glycosylation pattern following neoplastic transformation. Defining the glycan expression of an individual epitope within tissue sections using traditional approaches can be challenging [28, 29]. Improved diagnostics and treatment of cancer is one of the most challenging tasks for researchers today. The transformation from a normal cell into a tumor cell is a multistage process, typically a progression from a pre-cancerous lesion to malignant tumors. Despite the progress in developing new therapeutic modalities, cancer remains one of the leading diseases causing human mortality [30]. Detection of SA has been limited due to the lack of specific antibodies [9]. Here, we have used a highly specific SA-MIP for detection of SA on CLL cell lines. We suggest that SA-MIPs can be used for screening of different circulating tumor cells of various stages, including CLL cells. Further analysis of SA expression should include primary CLL cells from patient samples.

\section{Conclusions}

We have demonstrated SA expression on CLL cell lines with different levels of malignancy by using SA-MIPs. In conclusion, SA-MIPs can be used as plastic antibodies for detection of SA using both flow cytometry and fluorescence microscopy. SA-MIPs have high specificity and affinity for SA in different cell lines. In this context, we could detect differences of SA expression in CLL cell lines.

Acknowledgments This work was supported by grants from Malmö University, the Cancer Foundation at Malmö University Hospital, and The Swedish Knowledge Foundation.

Open Access This article is distributed under the terms of the Creative Commons Attribution 4.0 International License (http:// creativecommons.org/licenses/by/4.0/), which permits unrestricted use, distribution, and reproduction in any medium, provided you give appropriate credit to the original author(s) and the source, provide a link to the Creative Commons license, and indicate if changes were made.

\section{References}

1. Fuster MM, Esko JD. The sweet and sour of cancer: glycans as novel therapeutic targets. Nat Rev Cancer. 2005;5:526-42.

2. Fujita T, Satomura A, Hidaka M, Ohsawa I, Endo M, Ohi H. Inhibitory effect of free sialic acid on complement activation and 
its significance in hypocomplementemic glomerulonephritis. J Clin Lab Anal. 1999;13:173-9.

3. Ohtsubo K, Marth JD. Glycosylation in cellular mechanisms of health and disease. Cell. 2006;126:855-67.

4. Hoff SD, Matsushita Y, Ota DM, et al. Increased expression of sialyl-dimeric LeX antigen in liver metastases of human colorectal carcinoma. Cancer Res. 1989;49:6883-8.

5. Dennis JW, Laferte S, Yagel S, Breitman ML. Asparagine-linked oligosaccharides associated with metastatic cancer. Cancer Cells. 1989;1:87-92.

6. Seidenfaden R, Krauter A, Schertzinger F, Gerardy-Schahn R, Hildebrandt H. Polysialic acid directs tumor cell growth by controlling heterophilic neural cell adhesion molecule interactions. Mol Cell Biol. 2003;23:5908-18.

7. Ferreira JA, Videira PA, Lima L, et al. Overexpression of tumourassociated carbohydrate antigen sialyl-tn in advanced bladder tumours. Mol Oncol. 2013;7:719-31.

8. Cho J, Kushiro K, Teramura Y, Takai M. Lectin-tagged fluorescent polymeric nanoparticles for targeting of sialic acid on living cells. Biomacromolecules. 2014;15:2012-8.

9. Fujitani N, Furukawa J, Araki K, et al. Total cellular glycomics allows characterizing cells and streamlining the discovery process for cellular biomarkers. Proc Natl Acad Sci U S A. 2013;110:210510.

10. Xu X, Cheng H, Chen W, Cheng S, Zhuo R, Zhang X. In situ recognition of cell-surface glycans and targeted imaging of cancer cells. Sci Report. 2013;3.

11. Shinde S, El-Schich Z, Malakpour A, et al. Sialic acid-imprinted fluorescent Core-Shell particles for selective labeling of cell surface glycans. J Am Chem Soc. 2015;137:13908-12.

12. Liu A, Peng S, Soo JC, Kuang M, Chen P, Duan H. Quantum dots with phenylboronic acid tags for specific labeling of sialic acids on living cells. Anal Chem. 2010;83:1124-30.

13. Vasapollo G, Sole RD, Mergola L, et al. Molecularly imprinted polymers: present and future prospective. Int J Mol Sci. 2011;12: 5908-45.

14. Alexander C, Andersson HS, Andersson LI, et al. Molecular imprinting science and technology: a survey of the literature for the years up to and including 2003. J Mol Recognit. 2006;19:106-80.

15. Whitcombe MJ, Chianella I, Larcombe L, et al. The rational development of molecularly imprinted polymer-based sensors for protein detection. Chem Soc Rev. 2011;40:1547-71.

16. Kunath S, Panagiotopoulou M, Maximilien J, Marchyk N, Sänger J, Haupt K. Cell and tissue imaging with molecularly imprinted polymers as plastic antibody mimics. Adv Healthcare Mater. 2015;4:1322-6.
17. Lanemo Myhrinder A, Hellqvist E, Bergh A, et al. Molecular characterization of neoplastic and normal "sister" lymphoblastoid B-cell lines from chronic lymphocytic leukemia. Leuk Lymphoma. 2013;54:1769-79.

18. Cui H, Lin Y, Yue L, Zhao X, Liu J. Differential expression of the $\alpha 2,3$-sialic acid residues in breast cancer is associated with metastatic potential. Oncol Rep. 2011;25:1365-71.

19. Wang F, Cui S, Sun L, et al. High expression of $\alpha 2$, 3-linked sialic acid residues is associated with the metastatic potential of human gastric cancer. Cancer Detect Prev. 2009;32:437-43.

20. Damle RN, Ghiotto F, Valetto A, et al. B-cell chronic lymphocytic leukemia cells express a surface membrane phenotype of activated, antigen-experienced B lymphocytes. Blood. 2002;99:4087-93.

21. Klein U, Tu Y, Stolovitzky GA, et al. Gene expression profiling of B cell chronic lymphocytic leukemia reveals a homogeneous phenotype related to memory B cells. J Exp Med. 2001;194:1625-38.

22. Lowe JB. Glycan-dependent leukocyte adhesion and recruitment in inflammation. Curr Opin Cell Biol. 2003;15:531-8.

23. Varki NM, Varki A. Heparin inhibition of selectin-mediated interactions during the hematogenous phase of carcinoma metastasis: rationale for clinical studies in humans. Semin Thromb Hemost. 2002;28:53-66.

24. Laubli H, Stevenson JL, Varki A, Varki NM. Borsig L. L-selectin facilitation of metastasis involves temporal induction of Fut7dependent ligands at sites of tumor cell arrest. Cancer Res. 2006;66:1536-42.

25. Borsig L, Wong R, Hynes RO, Varki NM, Varki A. Synergistic effects of L- and P-selectin in facilitating tumor metastasis can involve non-mucin ligands and implicate leukocytes as enhancers of metastasis. Proc Natl Acad Sci U S A. 2002;99:2193-8.

26. Sgroi D, Varki A, Braesch-Andersen S. Stamenkovic I. CD22, a B cell-specific immunoglobulin superfamily member, is a sialic acidbinding lectin. J Biol Chem. 1993;268:7011-8.

27. Razi N, Varki A. Cryptic sialic acid binding lectins on human blood leukocytes can be unmasked by sialidase treatment or cellular activation. Glycobiology. 1999;9:1225-34.

28. Dhabangi A, Ainomugisha B, Cserti-Gazdewich C, et al. Effect of transfusion of red blood cells with longer vs shorter storage duration on elevated blood lactate levels in children with severe anemia: the TOTAL randomized clinical trial. JAMA. 2015:1-10.

29. Cummings RD. The repertoire of glycan determinants in the human glycome. Mol BioSyst. 2009;5:1087-104.

30. Chen H, Zhen Z, Todd T, Chu PK, Xie J. Nanoparticles for improving cancer diagnosis. Mater Sci Eng R Rep. 2013;74:35-69. 